\title{
Assessment of Leishmania major and Leishmania braziliensis promastigote viability after photodynamic treatment with aluminum phthalocyanine tetrasulfonate $\left(\mathrm{AIPCS}_{4}\right)$
}

Pinto JG (1), Soares CP (2), Mittmann J (1)

(1) Laboratory of Parasitology and Biotechnology, Research and Development Institute, Vale do Paraíba University (UNIVAP), São José dos Campos, São Paulo State, Brazil; (2) Laboratory of Cell Culture, Research and Development Institute, Vale do Paraíba University (UNIVAP), São José dos Campos, São Paulo State, Brazil.

\begin{abstract}
Cutaneous leishmaniasis is an infectious disease caused by protozoans of the genus Leishmania, which is transmitted through the bite of hematophagous insects of the genus Lutzomyia. This study aimed at testing in vitro the phototoxic effect of aluminum phthalocyanine tetrasulfonate ( IIPCS $_{4}$ ) on the viability of Leishmania major and Leishmania braziliensis. Stationary phase promastigote forms were treated with AlPcS$_{4}$ at $1.0 \mu \mathrm{M}$ and $10.0 \mu \mathrm{M}$ and incubated for one hour. Then $659 \mathrm{~nm}$ laser was applied at $5 \mathrm{and} 10 \mathrm{~J} / \mathrm{cm}^{2}$. Parasite viability was determined by differential count using the trypan blue dye exclusion method and by monitoring growth curves for nine days. Trypan blue exclusion assay showed a significant reduction of viable parasites compared to controls, L. major seemed more sensitive to the toxic effects of AIPcS 4 in the dark. The most effective photodynamic therapy (PDT) was obtained with AIPcS 4 at $10.0 \mu \mathrm{M}$ and $10 \mathrm{~J} / \mathrm{cm}^{2}$ whereas $L$. braziliensis showed the highest mortality rate after treatment.
\end{abstract}

Key words: cutaneous leishmaniasis, antiparasitic agents, Leishmania major, Leishmania braziliensis, AlPcS4, photodynamic therapy.

\section{INTRODUCTION}

American cutaneous leishmaniasis (ACL) is an infectious zoonotic disease caused by a protozoan of the Leishmania genus, transmitted through the bite of infected phlebotomine sand flies belonging to the Lutzomyia genus (1-3).

Cutaneous leishmaniasis is endemic in more than 70 countries worldwide and is a public health threat on four continents (the Americas, Europe, Africa, and Asia). The World Health Organization (WHO) considers ACL as one of the six main infectious diseases and one of the most common public health problems in the Americas, because of its high incidence, wide geographic distribution, and ability to produce deformities (3). From 1985 to 2005, in Brazil, an annual average of 28,568 autochthonous cases was recorded. In the 1980's, ACL was recorded in 19 states, and in 2003, autochthony was confirmed in all Brazilian states (4). According to the Center of Epidemiological Surveillance, 432 cases of leishmaniasis were registered in São Paulo state in 2009, with a further 162 cases in the first half of 2010 (5).

ACL is characterized in its cutaneous form by a single or multiple painless ulcerated lesions, mainly on exposed parts of the body including the face and limbs (3).

Conventional treatment is with pentavalent antimonials, first-line drugs, for at least 20 days. Antimony is indicated for treatment of all forms of cutaneous leishmaniasis, although mucosal forms require more care and may have slower response times and a higher relapse rate (6). The patient must be monitored for side effects; also, pentavalent antimonials cannot be administered to pregnant women or patients 
with renal or hepatic failure, cardiac arrhythmia, and Chagas' disease (3). Because conventional aggressive chemotherapy treatments are often unsatisfactory and produce undesirable side effects, the development of alternative treatments is of great importance.

Photodynamic therapy (PDT) has potential application in various areas of medicine, such as against cancer, skin diseases, and antimicrobial activity. PDT is currently being studied as an alternative treatment for ACL (7-17). Castano et al. (9-11) conducted an extensive review to clarify how sensitizers interact with target cells as reactive oxygen species are formed, how they are able to destroy tumor cells, and the mechanisms by which cell death may be triggered to help understand the processes caused by photodynamic therapy.

The effects of PDT in the in vitro and in vivo treatment of cutaneous leishmaniasis have been investigated. Several photosensitizers have been tested at different concentrations and different laser parameters, such as application time, wavelength, etc. Phthalocyanines, second generation photosensitizers for photodynamic therapy, such as zinc, chloroaluminum phthalocyanine and chloroaluminum phthalocyanine tetrasulfonate $\left(\mathrm{AlPcS}_{4}\right)$ have been studied and identified as promising agents (15, 18-20). $\mathrm{AlPcS}_{4}$ displays low toxicity, in vivo and in vitro studies, without high irradiation and more photodynamic-dependent cytotoxicity and antitumor effect in the red area of the spectrum $(>660$ $\mathrm{nm}$ ) where tissue penetration is high, showing considerable promise as a photosensitizer for PDT (19). The few clinical reports using PDT for treatment of cutaneous leishmaniasis have also shown promising results. Patients treated with ALA-PDT achieved a greater than $90 \%$ cure rate without evidence of recurrence $(21,22)$. Side effects from PDT observed in humans are transient burning sensation during illumination and subsequent hyperpigmentation $(21,23)$. PDT is less aggressive than conventional treatments which sometimes require hospitalization for patient monitoring, pushing up treatment costs. Also, the esthetic effects of PDT are superior to conventional treatments $(21,22)$.

In light of the promising findings using PDT to treat leishmaniasis, this study aimed to evaluate the phototoxic effect on viability and growth for Leishmania major and Leishmania braziliensis promastigotes treated with chloroaluminum phthalocyanine tetrasulfonate as the photosensitizer.

\section{MATERIALS AND METHODS}

\section{Parasites}

Leishmania major (MRHO/SU/1959/P) and Leishmania braziliensis (MHOM/BR/96/ LSC96-H3) were cultured in M199 medium and Schneider medium, respectively, supplemented with $10 \%$ heat-inactivated FBS, $2.5 \mu \mathrm{g} / \mathrm{mL}$ of hemin at $26^{\circ} \mathrm{C}$.

\section{Effect of AIPcS $_{4}$ on L. major and L. braziliensis Promastigotes}

Tests were performed with stationary phase promastigotes and all three independent assays were performed in triplicate. The photosensitizer chloroaluminum phthalocyanine tetrasulfonate $\left(\mathrm{AlPcS}_{4}\right)$ (Porphyrin Products Inc., USA) was previously prepared in PBS at $1 \mathrm{mM}$ and further diluted in the test concentrations. The experimental groups were divided as follows:

\section{$\rightarrow$ Group 1: controls}

- Untreated promastigotes maintained under regular culture.

- PS $1.0 \mu \mathrm{M}$ : promastigotes incubated with the photosensitizer at $1.0 \mu \mathrm{M}$ without irradiation.

- PS $10.0 \mu \mathrm{M}$ : promastigotes incubated with the photosensitizer at $1.0 \mu \mathrm{M}$ without irradiation.

$\rightarrow$ Group 2: promastigotes irradiated with energy densities of $5 \mathrm{~J} / \mathrm{cm}^{2}$

- Light control: promastigotes irradiated without photosensitizer.

- PDT 1.0 $\mu \mathrm{M}$ : promastigotes incubated with 1.0 $\mu \mathrm{M}$ of $\mathrm{AlPcS}_{4}$ and irradiated.

- PDT $10.0 \mu \mathrm{M}$ : promastigotes incubated with $10.0 \mu \mathrm{M}$ of $\mathrm{AlPcS}_{4}$ and irradiated.

$\rightarrow$ Group 3: promastigotes irradiated with energy densities of $10 \mathrm{~J} / \mathrm{cm}^{2}$

- Light control: promastigotes irradiated without photosensitizer.

- PDT 1.0 $\mu \mathrm{M}$ : promastigotes incubated with 1.0 $\mu \mathrm{M}$ of $\mathrm{AlPcS}_{4}$ and irradiated.

- PDT $10.0 \mu \mathrm{M}$ : promastigotes incubated with $10.0 \mu \mathrm{M}$ of $\mathrm{AlPcS}_{4}$ and irradiated.

The promastigotes, $1 \times 10^{6}$ parasites/well, were distributed in 24-well cell culture plates. For the tests, parasites were incubated with $\mathrm{AlPcS}_{4}$ at $1.0 \mu \mathrm{M}$ and $10.0 \mu \mathrm{M}$ for 60 minutes at $26^{\circ} \mathrm{C}$. The contents of each well were then centrifuged and 
sediment resuspended in fresh medium. Cells were then irradiated with a near infrared $(\lambda 659$ $\mathrm{nm}, 40 \mathrm{~mW}$ ) GaAlAs laser diode semiconductor (Kondortech Equipamentos Odontológicos Ltda, Brazil). Equipment calibration was measured by an Espectra Pro 2500i spectrometer (PiAction, USA).

Cell viability was determined by differential count of dead and live parasites using the trypan blue dye exclusion method (15). Parasite survival after treatment was monitored by growth curve. Growth was microscopically determined by daily counts of parasite numbers in a hemocytometer for nine days. Results correspond to three independent assays performed in triplicate. Inhibition of parasite growth was determined by comparison to untreated controls.

\section{Statistical Analysis}

Data were analyzed using ANOVA (BioStat $5.0^{\circledR}$ program, Brazil) and results were considered significant when $p<0.05$.

\section{RESULTS}

Phototoxic Effect of AlPcS in L. major and $L$. braziliensis Promastigotes

There were no differences in cell viability between L. major promastigotes treated with photosensitizer without irradiation and submitted to PDT, except for the highest photosensitizer concentration and highest irradiation level 10 $\mathrm{J} / \mathrm{cm}^{2}$. The viability of $L$. major promastigotes treated only with photosensitizer statistically differed from the control group (Figure $1-\mathrm{A}$ ), thus indicating a toxic effect from the photosensitizer. The opposite was observed in L. braziliensis where the groups treated with photosensitizer showed no significant difference to controls (Figure 1 B). These results suggest that $\mathrm{AlPcS}_{4}$ is more toxic to $L$. major than to L. braziliensis. The highest percentage of deaths were observed (about 99\%) in L. braziliensis promastigotes, with the higher photosensitizer concentration of $10.0 \mu \mathrm{M}$ and irradiation of $10 \mathrm{~J} / \mathrm{cm}^{2}$ (Figure $1-\mathrm{B}$ ).

Ours results show a significant reduction in parasite survival by the trypan blue dye exclusion method $(p<0.01)$ compared to controls for groups receiving photodynamic therapy in both Leishmania species (Figure 1 - A and B) except for L. braziliensis treated with $1.0 \mu \mathrm{M}$ and $5 \mathrm{~J} / \mathrm{cm}^{2}$ (Figure $1-B$ ). Promastigotes irradiated without phthalocyanine showed no significant difference
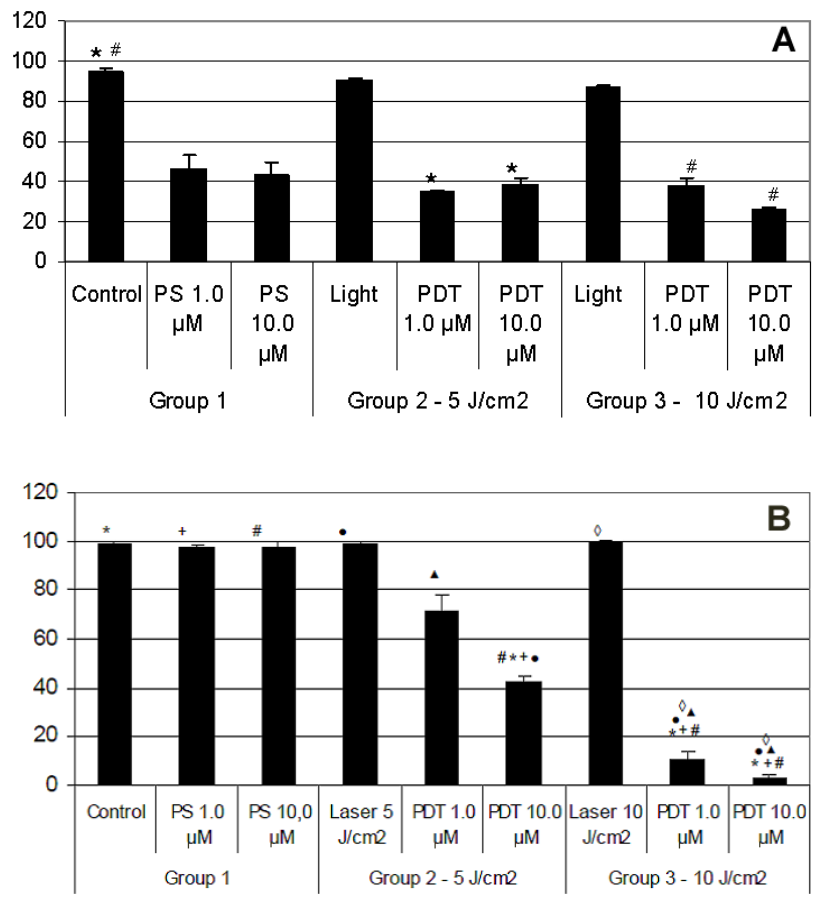

Figure 1. Promastigote viability analyzed by the trypan blue dye exclusion method after photodynamic therapy with AlPcS. (A) Leishmania major, (B) Leishmania braziliensis. The same symbols represent statistical differences between groups at a significance level of $p>0.05$ to Leishmania major and $p>0.01$ to Leishmania braziliensis.

to their control groups (Figure $1-\mathrm{A}$ and $\mathrm{B}$ ) indicating that the laser energy densities tested do not reduce promastigote viability.

\section{Survival of Promastigotes in Culture after PDT}

Analysis of L. major growth curves (Figure 2 - A and B) shows that there were no significant differences in growth for the control group and groups treated with both laser energy densities (Table 1). A significant difference in parasite growth $(p<0.01)$ was observed between the control group and the groups which received only $\mathrm{AlPcS}_{4}$ in concentrations of $1.0 \mu \mathrm{M}$ and 10.0 $\mu \mathrm{M}$. This was expected because parasite death was seen after incubation of promastigotes with phthalocyanine only (Table 1).

Parasite growth was significantly different $(p<0.01)$ between the control group and groups treated with $1.0 \mu \mathrm{M}$ and $10.0 \mu \mathrm{M} \mathrm{AlPcS}_{4}$ photodynamic therapy at both energy densities ( 5 $\mathrm{J} / \mathrm{cm}^{2}$ and $10 \mathrm{~J} / \mathrm{cm}^{2}$ ). Growth curves for parasites treated with phthalocyanine and those submitted 

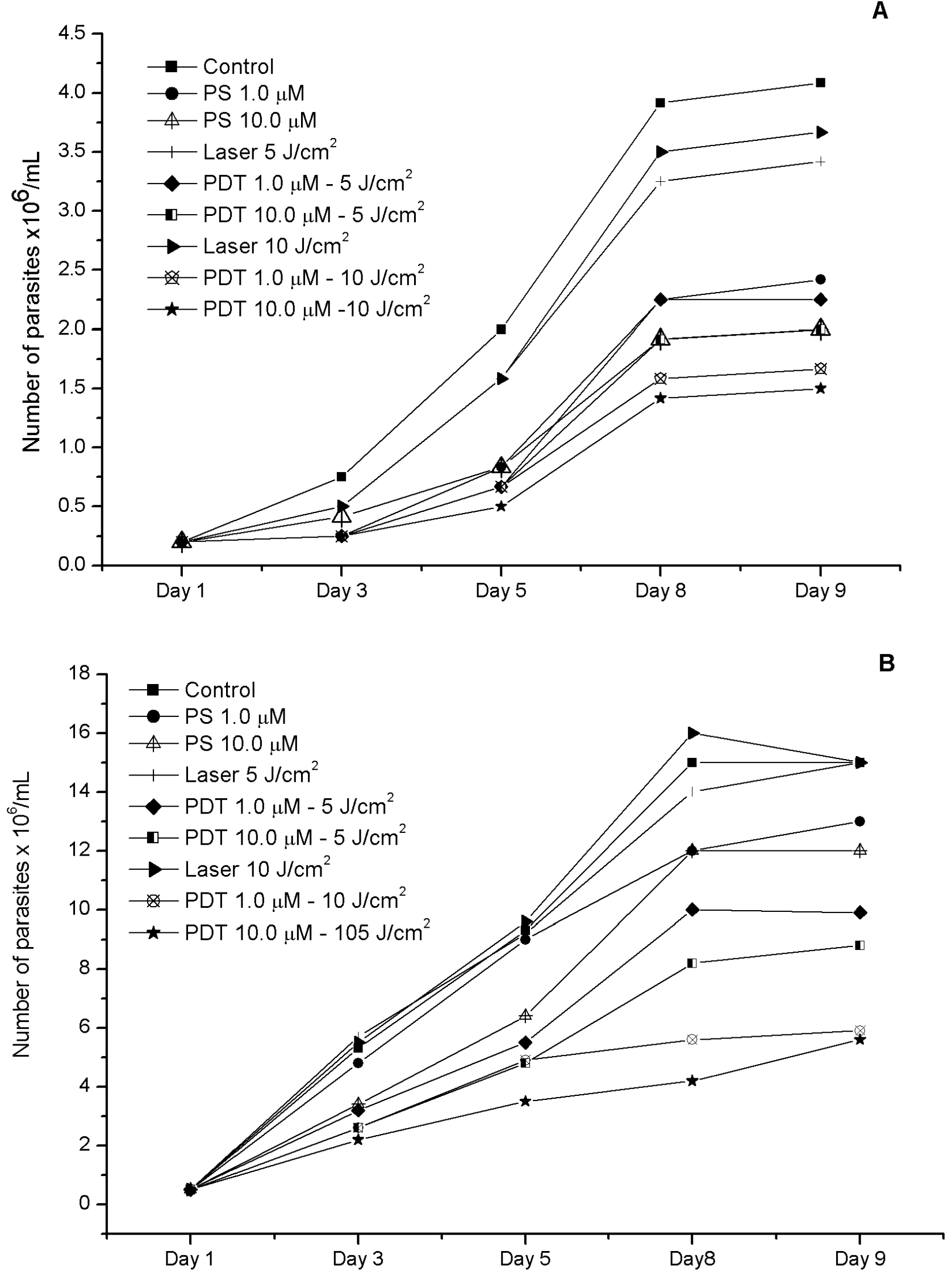

Figure 2. Growth curves for promastigotes after photodynamic treatment. (A) Growth curves for Leishmania major after PDT with AIPCS $_{4}$ and laser at $5 \mathrm{~J} / \mathrm{cm}^{2}$ and after PDT with laser at $10 \mathrm{~J} / \mathrm{cm}^{2}$. (B) Growth curves for Leishmania braziliensis after PDT with AIPcS and Laser at $5 \mathrm{~J} / \mathrm{cm}^{2}$ and after PDT with AIPCS $_{4}$ and laser at 10 $\mathrm{J} / \mathrm{cm}^{2}$. 
to PDT with $5 \mathrm{~J} / \mathrm{cm}^{2}$ were similar, suggesting that the tested $\mathrm{AlPcS}_{4}$ doses are toxic to L. major. The most promising results were obtained with 10.0 $\mu \mathrm{M}$ phthalocyanine and $10 \mathrm{~J} / \mathrm{cm}^{2}$ irradiation.

For L. braziliensis (Figure 2 - B) no significant differences were observed between promastigote growth in the control group and the groups treated with laser without phthalocyanine. However, for L. major a significant difference was observed $(p<0.05)$ in promastigote growth over nine days compared to the control group and those which received $\mathrm{AlPcS}_{4}$ treatment without laser irradiation $(p<0.05)$. This corroborated the viability data, where the tested concentrations of $\mathrm{AlPcS}_{4}$ were not toxic to $L$. braziliensis promastigotes (Table 1).

The lowest survival rates were observed when promastigotes were irradiated with $10 \mathrm{~J} /$ $\mathrm{cm}^{2}$ at both photosensitizer concentrations, suggesting that energy dose is important for L. braziliensis promastigotes where even at the lowest photosensitizer concentration, the photoantimicrobial effect was more intense than in $L$. major.

Table 1. Comparative results for Leishmania major and Leishmania braziliensis promastigotes growth after PDT with $\mathrm{AlPcS}_{4}$

\begin{tabular}{|c|c|c|c|c|}
\hline \multirow{2}{*}{\multicolumn{3}{|c|}{ Treatments }} & \multicolumn{2}{|c|}{ Number of parasites $\times 10^{6} / \mathrm{mL}$} \\
\hline & & & \multirow{2}{*}{$\begin{array}{l}\text { L. major } \\
4.1 \pm 0.4^{*}\end{array}$} & \multirow{2}{*}{$\begin{array}{c}\text { L. braziliensis } \\
15 \pm 2.2^{*}\end{array}$} \\
\hline Group 1 & Un & cells & & \\
\hline & PS & $1.0 \mu \mathrm{M}$ & $2.4 \pm 0.3^{\dagger}$ & $13 \pm 3.5^{\dagger}$ \\
\hline & & $10.0 \mu \mathrm{M}$ & $2.0 \pm 0.3^{\#}$ & $12 \pm 3.5^{\#}$ \\
\hline \multirow[t]{3}{*}{ Group 2} & $5 \mathrm{~J} / \mathrm{cm}^{2}$ & Light & $3.4 \pm 0.6^{\S}$ & $15 \pm 1.8^{\S}$ \\
\hline & & $1.0 \mu \mathrm{M}$ & $2.3 \pm 0.3$ & $9.9 \pm 1.9^{*+\# \S+}$ \\
\hline & & $10.0 \mu \mathrm{M}$ & $2.0 \pm 0.6^{*+\# \S}$ & $8.8 \pm 1.5^{*+\# \S+}$ \\
\hline \multirow[t]{3}{*}{ Group 3} & $10 \mathrm{~J} / \mathrm{cm}^{2}$ & Light & $3.7 \pm 0.6^{+}$ & $15 \pm 4.8^{+}$ \\
\hline & & $1.0 \mu \mathrm{M}$ & $1.7 \pm 0.1$ & $5.9 \pm 2.2^{*+\# \S+}$ \\
\hline & & $10.0 \mu \mathrm{M}$ & $1.5 \pm 0.3^{*+\# \S+}$ & $5.6 \pm 1.7^{*+\# \S+}$ \\
\hline
\end{tabular}

Data represent the number of parasites after nine days of cultivation. The same symbols represent statistical differences between groups ${ }^{*} p<0.05$ vs control; ${ }^{\dagger} p<0.05$ vs PS $1.0 \mu \mathrm{M} ;{ }^{\#} p<0.05$ vs PS $10.0 \mu \mathrm{M} ;{ }^{\S} p<0.05$ vs laser at $5 \mathrm{~J} / \mathrm{cm}^{2}$; and ${ }^{+} p<0.05$ vs laser at $10 \mathrm{~J} / \mathrm{cm}^{2}$.

\section{DISCUSSION}

This work demonstrated the phototoxic effect of chloroaluminum phthalocyanine tetrasulfonate $\left(\mathrm{AlPcS}_{4}\right)$ on Leishmania major and Leishmania braziliensis promastigotes. Similar results were demonstrated by Escobar et al. (24) with L. panamensis and L. chagasi using aluminum phthalocyanine chloride zinc phthalocyanine as the photosensitizer to reduce cell viability and inhibit growth in vitro. Aluminum phthalocyanine chloride at 0 to 10 $\mu \mathrm{g} / \mathrm{mL}$ was also phototoxic to intracellular and extracellular forms of Leishmania amazonensis when irradiated with $3.6 \mathrm{~J} / \mathrm{cm}^{2}$ with no effects on non-irradiated parasites or macrophages (15).

Phototoxic effects against promastigotes depend on factors such as phthalocyanine type, concentration, and charge as well as Leishmania species (25). In this study, L. major was more sensitive to the toxic effects of $\mathrm{AlPcS}_{4}$. Even in the dark, L. major viability decreased, whereas no cytotoxicity was observed in $L$. braziliensis without illumination.

Phthalocyanine type and concentration, and laser strength $\left(\mathrm{J} / \mathrm{cm}^{2}\right)$ are also important factors which require consideration in antimicrobial photochemotherapy. Some molecules do not exhibit the desired phototoxic effect as demonstrated when zinc phthalocyanine stabilized in sol-gel $\mathrm{TiO}_{2}$ was not phototoxic to $L$. chagasi or L. panamensis promastigotes (26).

Studies by Akilov et al. (25) suggest that molecular charges and structure are important 
efficiency factors in PDT against Leishmania because cationic benzophenoxazine analogs were more effective than anionic photosensitizers. Also, the same compound can exhibit different degrees of toxicity depending on species tested. The same effect was observed in classical antitumor PDT, where the effectiveness of therapy was related to appropriate photosensitizing, tumor type, photosensitizer concentration, and irradiation (9-11).

Although no studies were found on use of $\mathrm{AIPcS}_{4}$ as photosensitizer in Leishmania PDT, anti-parasitic mechanisms are still unknown. In a study using PDT with $\mathrm{AIPcS}_{4}$ for $T$. foetus amitochondrial protozoa, the type of cell death induced by PDT was not necrosis and the authors suggested it may have been apoptotic or autophagic cell death (27). In a previous work, a MTT assay showed that PDT with 10.0 $\mu \mathrm{M}$ of AlPcS4 and 5 and $10 \mathrm{~J} / \mathrm{cm}^{2}$ reduced $L$. major mitochondrial activity. It is therefore possible that cell death in Leishmania is related to apoptosis mediated by photosensitizing action on mitochondria. Subcellular $\mathrm{AlPcS}_{4}$ fluorescence has been correlated with granules predominantly located at one cytoplasm site in the vicinity of the nucleus, with an initial increase in fluorescence intensity followed by photobleaching $(28,29)$. In Hep-2 cells, PDT with $\mathrm{AlPcS}_{4}$ led to significant alterations in mitochondria, causing potential membrane loss, alteration in cardiolipin distribution, and cell death, thereby suggesting an initially faster process of the intrinsic death pathway, considerably decreasing cell viability in a short time $(29,30)$. For carbaporphyrin ketals used in Leishmania tarontelae, the presence of reactive oxygen species, such as singlet oxygen and superoxide radicals, was associated with superoxide oxidation of the probe in the mitochondria with an increase in compound concentration (31).

In assays with other photosensitizers such as 3.7-bis (di-n-butylamino) phenothiazin-5-ium bromide PPA904, fluorescence was observed immediately after treatment application and parasite death occurred in the initial minutes of treatment; after that parasite load remained unchanged $(32,33)$. Topically applied PPA904 cream in the ears of mice to treat cutaneous leishmaniasis was irradiated with a wavelength of $665 \pm 15 \mathrm{~nm}$ at $50 \mathrm{~J} / \mathrm{cm}^{2}\left(50 \mathrm{~mW} / \mathrm{cm}^{2}\right)$ and decreased parasite load (32).
Ours results are consistent with other studies showing that PDT alone was not sufficient to eradicate parasites (34). We observed reduced cell viability, but some parasites remained alive and were able to grow.

Changes in photosensitizer delivery system might improve phototoxic action. Acenaphthoporphyirins combined with artificial liposomes of dimyristoyl phosphatidylcholine (DMPC) and artificial liposomes from a mixture of DMPC, cholesterol, and distearoyl phosphatidylglycerol (DSPG) were able to carry porphyrins to Leishmania tarentolae promastigotes and liposome associated compounds were effective against in vitro Leishmania panamensis amastigotes, but zinc phthalocyanine stabilized in $\mathrm{TiO}_{2}$ sol-gel was not phototoxic to $L$. chagasi or $L$. panamensis promastigotes $(26,34)$.

Experiments with application of aminolevulinic acid (ALA) irradiated at $635 \mathrm{~nm}$ and $50 \mathrm{~J} / \mathrm{cm}^{2}$ efficiently eradicated the parasite and initiated a rigorous inflammatory response (21). However, phototoxicity in this case is more associated to a macrophage death triggered response (21).

The results presented in this study reinforce the possible use of PDT in the treatment of American cutaneous leishmaniasis. Despite a favorable result, $\mathrm{AlPcS}_{4}$ has the limitation of being toxic to L. major promastigotes without irradiation at the tested concentrations. An ideal compound would only damage the cell after interaction with light. An aspect that should be considered in PDT for ACL treatment is absence of resistance, as aspects of the host-parasite relationship in Leishmania spp. can be neutralized by photodynamic antimicrobial treatments (35). These findings suggest that it is valid to test and develop new photosensitizers to determine whether they are directly effective against amastigotes and other Leishmania species, and to select those with greatest therapeutic potential for use in treating cutaneous leishmaniasis. PDT tests with in vivo models should be conducted to better understand the mechanisms and therapeutic potential of PDT in treating cutaneous leishmaniasis patients.

\section{ACKNOWLEDGMENTS}

The authors are grateful to Dr. Ângela K. Cruz for providing Leishmania major parasites, Dr. Mário Steindel for Leishmania braziliensis parasites, Dr. Cibelle Barbosa Lopes for laser equipment, 
Dr. Newton Soares from the Laboratory of Cell and Tissue Biology, Maira Gaspar Tosato for laser measurement equipment, and Prof. A. A. Martin for the use of the Espectra Pro $2500 \mathrm{i}^{\circ}$ spectrometer (PiAction). We are also grateful to the Coordination for the Improvement of Higher Education Personnel (CAPES) for the fellowship offered to Juliana Guerra Pinto and Valeparaibana Education Foundation (FVE) for their financial support.

\section{COPYRIGHT}

(C) CEVAP 2011

\section{SUBMISSION STATUS}

Received: February 1, 2011.

Accepted: May 26, 2011.

Abstract published online: June 1, 2011. Full paper published online: August 31, 2011.

\section{CONFLICTS OF INTEREST}

There are no conflicts of interest.

\section{FINANCIAL SOURCE}

Valeparaibana Education Foundation (FVE) provided the financial grants.

\section{ETHICS COMMITTEE APPROVAL}

This study was approved by the Ethics Committee of Vale do Paraíba University (UNIVAP), process number I034CEP/2009.

\section{CORRESPONDENCE TO}

JOSANE MITTMANN, Instituto de Pesquisa e desenvolvimento, UNIVAP, Av. Shishima Hifumi, 2911, Urbanova, São José dos Campos, SP, 12244000, Brazil. Phone: +55 123947 1160. Email: mittmann@univap.br.

\section{REFERENCES}

1. Basano SA, Camargo LMA. Leishmaniose tegumentar americana: histórico, epidemiologia e perspectivas de controle. Rev Bras Epidemiol. 2004;7(3):329-37.

2. Sampaio RNR, Lucas IC, Takami HL. Inefficacy of the association $\mathrm{N}$-methyl glucamine and topical miltefosine in the treatment of experimental cutaneous leishmaniasis by Leishmania (Leishmania) amazonensis. J Venom Anim Toxins incl Trop Dis. 2007;13(3):598-606.

3. Camargo LB, Langoni H. Impact of leishmaniasis on public health. J Venom Anim Toxins incl Trop Dis. 2006;12(4):527-48.

4. Ministério da Saúde. Secretaria de Vigilância em Saúde. Manual de Vigilância da Leishmaniose
Tegumentar Americana / Ministério da Saúde, Secretaria de Vigilância em Saúde [Internet]. 2nd ed. Brasília: Editora do Ministério da Saúde; 2007. 180 p.

5. Centro de Vigilância Epidemiológica. Leishmaniose tegumentar americana [Internet]. São Paulo: Secretária de Saúde. [cited 2010 Aug 30]. Available from: http:// www.cve.saude.sp.gov.br/htm/zoo/lta_gve.htm.

6. Gontijo B, Carvalho MLR. Leishmaniose tegumentar americana. Rev Soc Bras Med Trop. 2003;36(1):71-80.

7. Sohl S, Kauer F, Paasch U, Simon JC. Photodynamic treatment of cutaneous leishmaniasis. J Dtsch Dermatol Ges. 2007;5(2):128-30.

8. Machado AEH. Terapia fotodinâmica: princípios, potencial de aplicação e perspectivas. Quim Nova. 2000;23(2):237-43.

9. Castano AP, Demidova TN, Hamblin MR. Mechanisms in photodynamic therapy: part one - photosensitizers, photochemistry and cellular localization. Photodiag Photodyn Ther. 2004;1(1):279-93.

10. Castano AP, Demidova TN, Hamblin MR. Mechanisms in photodynamic therapy: part two cellular signaling, cell metabolism and models of cell death. Photodiag Photodyn Ther. 2005;2(1):1-23.

11. Castano AP, Demidova TN, Hamblin MR. Mechanisms in photodynamic therapy: part three -Photosensitizer pharmacokinetics, biodistribution, tumor localization and modes of tumor destruction. Photodiag Photodyn Ther. 2005;2(1):91-106.

12. Recio ED, Zambrano B, Alonso ML, de Eusebio E, Martín M, Cuevas J, et al. Topical 5-aminolevulinic acid photodynamic therapy for the treatment of unilesional mycosis fungoides: a report of two cases and review of the literature. Int J Dermatol. 2008;47(4):410-3.

13. Akilov OE, O’Riordan $\mathrm{K}$, Kosaka S, Hasan $\mathrm{T}$. Photodynamic therapy against intracellular pathogens: problems and potentials. Med Laser Appl. 2006;21(1):251-60.

14. Akilov OE, Kosaka S, Maytin EV, Hasan T. Prospects for the use of differentiation-modulating agents as adjuvant of photodynamic therapy for proliverative dermatoses. J Dermatol. 2008;35(4):197-205.

15. Dutta S, Ray D, Kolli BK, Chang KP. Photodynamic sensitization of Leishmania amazonensis in both extracellular and intracellular stages with aluminum phthalocyanine chloride for photolysis in vitro. Antimicrob Agents Chemother. 2005;49(11):4474-84.

16. Huang Z. A review of progress in clinical photodynamic therapy. Technol Cancer Res Treat. 2005;4(3):283-93.

17. MacCormack MA. Photodynamic therapy in dermatology: an update on applications and outcomes. Semin Cutan Med Surg. 2008;27(1):52-62

18. Alexandratou E, Yova D, Loukas S. A confocal microscopy study of very early cellular response to oxidative stress induces by zinc phthalocyanine sensitization. Free Radic Biol Med. 2005;39(9):111927.

19. Koshida K, Hisazumi H, Komatsu K, Hirata A, Uchibayashi T. Possible advantages of aluminumchloro-tetrasulfonated phthalocyanine over hematoporphyrin derivative as a photosensitizer in 
photodynamic therapy. Urol Res. 1993;21(4):283-8.

20. Montanari J, Perez AP, Di Salvo F, Diz V, Barnadas $\mathrm{R}$, Dicelio L, et al. Photodynamic ultradeformable liposomes: design and characterization. Int J Pharm. 2007;330(1-2):183-94.

21. Akilov OE, Kosaka S, O'Riordan K, Hasan T. Parasiticidal effect of delta-aminolevulinic acid-based photodynamic therapy for cutaneous leishmaniasis is indirect and mediated through the killing of the host cells. Exp Dermatol. 2007;16(8):651-60.

22. Asilian A, Davami M. Comparison between the efficacy of photodynamic therapy and topical paromomycin in the treatment of Old World cutaneous leishmaniasis: a placebo-controlled, randomized clinical trial. Clin Exp Dermatol. 2006;31(5):634-37.

23. Gardlo K, Horska Z, Enk CD, Rauch L, Megahead M, Ruzicka T, et al. Treatment of cutaneous leishmaniasis by photodynamic therapy. J Am Acad Dermatol. 2003;48(6):893-6.

24. Escobar P, Hernández IP, Rueda CM, Martínez F, Páez E. Photodynamic activity of aluminum (III) and zinc (II) phthalocyanines in Leishmania promastigotes. Biomedica. 2006;26 Suppl1:49-56.

25. Akilov OE, Kosaka S, O'Riordan K, Song X, Sherwood $\mathrm{M}$, Flotte TJ, et al. The role of photosensitizer molecular charge and structure on the efficacy of photodynamic therapy against Leishmania parasites. Chem Biol. 2006;13(8):839-47.

26. Lopez T, Ortiz E, Alvarez M, Navarrete J, Odriozola JA, Martinez-Ortega F, et al. Study of the stabilization of zinc phthalocyanine in sol-gel TiO2 for photodynamic therapy applications. Nanomedicine. 2010;6(6):77785.

27. da Silva NS, Ribeiro Cde M, Machado AH, PachecoSoares C. Ultrastructural changes in Tritrichomonas foetus after treatments with AlPcS4 and photodynamic therapy. Vet Parasitol. 2007;146(1-2):175-81.

28. Ruck A, Beck G, Bachor R, Akgun N, Gschwend $\mathrm{MH}$, Steiner R. Dynamic fluorescence changes during photodynamic therapy in vivo and in vitro of hydrophilic A1 (III) phthalocyanine tetrasulphonate and lipophilic Zn (II) phthalocyanine administered in liposomes. J Photochem Photobiol B. 1996;36(2):12733.
29. Machado AH, Pacheco Soares C, da Silva NS, Moraes KC. Cellular and molecular studies of the initial process of the photodynamic therapy in HEp-2 cells using LED light source and two different photosensitizers. Cell Biol Int. 2009;33(7):785-95.

30. Tamietti BF, Machado AH, Mauftoum-Costa M, DA Silva NS, Tedesco AC, Pacheco-Soares C. Analysis of mitochondrial activity related to cell death after PDT with AlPCS4. Photomed Laser Surg. 2007;25(3):175-9.

31. Morgenthaler JB, Peters SJ, Cedeño DL, Constantino $\mathrm{MH}$, Edwards KA, Kamowski EM, et. al Carbaporphyrin ketals as potential agents for a new photodynamic therapy treatment of leishmaniasis. Bioorg Med Chem. 2008;16(14):7033-8.

32. Akilov OE, Yousaf W, Lukjan SX, Verma S, Hasan T. Optimization of topical photodynamic therapy with 3,7-bis(di-n-butylamino)phenothiazin-5-ium bromide for cutaneous leishmaniasis. Lasers Surg Med. 2009;41(5):358-65.

33. Latorre-Esteves E, Akilov OE, Rai P, Beverley SM, Hasan T. Monitoring the efficacy of antimicrobial photodynamic therapy in a murine model of cutaneous leishmaniasis using L. major expressing GFP. J Biophotonics. 2010;3(5-6):328-35.

34. Gardner DM, Taylor VM, Cedeño DL, Padhee $\mathrm{S}$, Robledo SM, Jones MA, et al. Association of acenaphthoporphyrins with liposomes for the photodynamic treatment of leishmaniasis. Photochem Photobiol. 2010;86(3):645-52.

35. Baptista MS, Wainwright $M$. Photodynamic antimicrobial chemotherapy (PACT) for the treatment of malaria, leishmaniasis and trypanosomiasis. Braz J Med Biol Res. 2011; 44(1):1-10. 